\title{
Assessment of casual blood pressure variations
}

\author{
Thomas Thulin \\ M.D.
}

\section{Bo BENGTSSON M.D.}

\author{
BENGT SCHERSTÉN \\ M.D. \\ The Dalby Community Research Centre and Department of Internal Medicine, \\ University Hospital, Lund, Sweden
}

\begin{abstract}
Summary
All residents in a suburban community in southern Sweden, 8 years of age and older, were invited to an ophthalmological examination. The examination included a blood pressure determination.

Of the 1917 persons invited $85.5 \%$ took part in the study. $3.5 \%$ of these were excluded because they were taking antihypertensive drugs. The investigations were conducted during 14 consecutive months and at different times of the day.

The systolic and diastolic blood pressure distribution curves exhibited a positive skewing. The blood pressures rose to a plateau with essentially unchanged pressures in the age groups 28-32 years up to 38-42 years. In these ages, the systolic blood pressure was significantly higher among the males than among the females. The relation was reversed in the age groups above 48 years. The diastolic blood pressure showed no significant sex differences in the various age groups.
\end{abstract}

A multiple linear regression analysis was used to determine whether there were diurnal and seasonal effects on the blood pressure independent of the age and sex. The systolic blood pressure during the winter months was $4 \cdot 1$ and $5.0 \mathrm{mmHg}$ higher in the male and female subjects respectively, while the diastolic blood pressure during the winter months was 1.7 and 1.9 mmHg higher in the male and female subjects respectively. The time of day had no effect on the systolic blood pressure while the diastolic blood pressure increased by 0.24 and $0.27 \mathrm{mmHg} / \mathrm{hr}$ from 8 a.m. to 9 p.m. in the male and female subjects respectively.

It is concluded that the small genuine effects of the time of measurement of casual blood pressure lack practical importance in screening of hypertension.

\section{Introduction}

Many investigations conducted in representative samples of different populations have shown that

Correspondence and request for reprints to: Dr Thomas Thulin, M.D., The Unit for Community Care Sciences, S-240 10 Dalby, Sweden. the systolic and diastolic blood pressures increase with age (Hamilton et al., 1954; Bøe, Humerfelt and Wedervang, 1957; Comstock, 1957; Miall and Lovell, 1967). The elevation of blood pressure with age is greater in females than in males (Kagan et al., 1958). The distributions of both systolic and diastolic blood pressures are considered to be unimodal but to manifest a skew to the right (Epstein, 1960).

The variation in blood pressure with the time of day has been studied in small groups of selected individuals. The blood pressure decreases appreci ably during sleep but contradictory results have beero obtained with respect to variations in blood pressure during the waking hours (Kain, Hinman and Soko low, 1964; Richardson et al., 1964; Athanassiadis et al., 1969; Irving et al., 1974).

With one exception (Sasaki et al., 1969) studies of seasonal variations in blood pressure have also been conducted on selected groups of patients (Brown, 1930; Rose, 1961; Palmai, 1962; Paul et al., 1963). The results suggest that the blood pressure is lowest during the warm season of the year.

Variations in blood pressure with season and time of day might be important both for patient care and for community-based studies of hypertension. The present study was undertaken to investigate these points further as a preliminary to a more comprehensive study of hypertension.

\section{Material}

The material was derived from a general ophthalmic population survey carried out at the Dalby Community Care Centre in southern Sweden from March 1969 to April 1970. Invitations with an appointment notification and a brief questionnaire were mailed in rotation, following a directory, to all persons, aged 8 years or more, who had been resident in the village, surrounding the Centre, since December 1968. The fact that a measurement of the blood pressure was part of the examination was not mentioned in the invitation. The questionnaire included a question as to what present medications 
were being used. Examinations were conducted from 8 a.m. to 9 p.m. In order to improve attendance, alterations of appointments were encouraged.

Of 1917 persons invited $1703(89 \%)$ took part in the survey. Sixty-seven persons using drugs listed in a Swedish pharmacopoeia (Farmaceutiska specialiteter $i$ Sverige, 1969) under the heading 'agents in hypertension' were excluded from the present study. The blood pressure measurement was omitted in sixty-six cases-usually because applanation tonometry was impossible or unreliable. Age and sex distributions are given in Table 1. Information about non-participants and persons not applanated has been given in an earlier report (Bengtsson, 1972).

\section{Methods}

The systolic blood pressure and diastolic (phase five) blood pressures were measured on the right arm immediately after the subject had assumed the recumbent position. One mercury manometer and cuffs of three different sizes $(9 \times 28,12 \times 35$ and $15 \times 43 \mathrm{~cm})$ were used. The readings were determined to the nearest $5 \mathrm{mmHg}(1 \mathrm{mmHg} \approx 0.133 \mathrm{kPa})$. All measurements were made by the same nurse. The room temperature was $21-23^{\circ} \mathrm{C}$.

The time of day was noted in whole hours. In order to obtain an expression for season, a dummy variable was assigned the value 0 (zero) for persons attending during the months May-October-and the value 1 for others. This classification was adopted since the mean temperature at Dalby is highest for May-October and lowest for November-April (Statistisk årsbok, 1970; Lunds kommun: Statistisk årsbok, 1972).

All data were recorded immediately on special forms. Transfer to punch cards and further treatment were performed at the Computer Centre in Lund.

The multiple regression analysis was carried out with a standard computer program (BMD 02R) (Dixon, 1970). For polynomial approximation, in accordance with the least square criterion, a method of orthogonalization (Björck and Dahlkvist, 1974) was used.
The hypothesis that no differences existed between mean values of two groups was checked with Student's $t$-test.

All values are given as mean \pm s.d. unless otherwise stated.

\section{Results}

1. Blood pressure and age

Table 2 shows the mean values for the systolic and diastolic blood pressures within the different male and female age groups. The systolic and the diastolic blood pressures increased with age (see also Fig. 1). The increase was most pronounced for the systolic blood pressure.

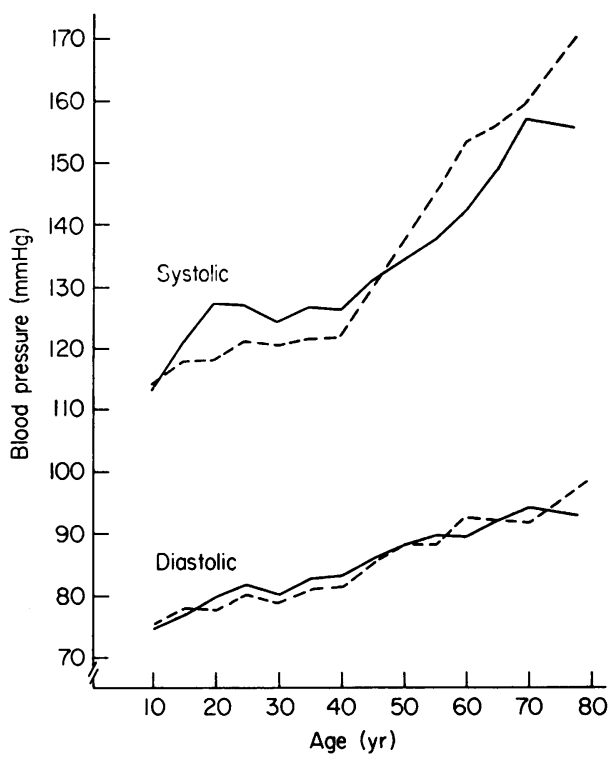

FIG. 1. Systolic and diastolic mean blood pressures and age. Males $=\longrightarrow(n=780)$, females $=----$ $(n=790)$. Conversion from traditional units to SI units: $1 \mathrm{mmHg} \approx 0.133 \mathrm{kPa}$.

TABLE 1. Number of invited, attending, untreated and examined men and women in different age groups

\begin{tabular}{|c|c|c|c|c|c|c|c|c|}
\hline \multirow{2}{*}{$\begin{array}{l}\text { Age } \\
\text { (years) }\end{array}$} & \multicolumn{2}{|c|}{ Invited } & \multicolumn{2}{|c|}{ In attendance } & \multicolumn{2}{|c|}{ Untreated } & \multicolumn{2}{|c|}{ Examined } \\
\hline & Men & Women & Men & Women & Men & Women & Men & Women \\
\hline $8-9$ & 48 & 45 & 46 & 43 & 46 & 43 & 44 & 38 \\
\hline $10-19$ & 160 & 147 & 141 & 134 & 141 & 134 & 133 & 128 \\
\hline 20-29 & 158 & 166 & 127 & 154 & 127 & 154 & 125 & 149 \\
\hline $30-39$ & 179 & 172 & 160 & 163 & 160 & 163 & 155 & 158 \\
\hline $40-49$ & 141 & 132 & 120 & 117 & 120 & 112 & 116 & 105 \\
\hline $50-59$ & 107 & 102 & 93 & 94 & 90 & 85 & 90 & 82 \\
\hline $60-69$ & 95 & 97 & 86 & 86 & 76 & 75 & 75 & 73 \\
\hline 70-79 & 48 & 74 & 40 & 62 & 34 & 48 & 33 & 46 \\
\hline $80-$ & 18 & 28 & 15 & 22 & 12 & 16 & 9 & 11 \\
\hline Total & 954 & 963 & 828 & 875 & 806 & 830 & 780 & 790 \\
\hline
\end{tabular}


In the male subjects the systolic blood pressure rose significantly $(P<0.001)$ from one age group to the next in the interval 8 to 22 years. Thereafter, the systolic blood pressure remained essentially unchanged $(P>0.05)$ up to the 38-42-year-old age group. Among subjects 43 years or older there was a significant positive correlation between blood pressure and age $(P<0.001)$.

In the female subjects the systolic blood pressure rose significantly from the 8-12-year-old age group to the 13-17-year-old age group $(P<0.01)$ and also from the 18-22-year-old age group to the 23-27year-old age group $(P<0.05)$. Thereafter, the systolic blood pressure remained essentially unchanged $(P>0.05)$ up to the 38-42-year-old age group. In older females the blood pressure again had a significant positive correlation with age $(P<0.001)$.

The diastolic blood pressure appeared to increase more steadily with age, even if there was a tendency for the curve to level out somewhat in the interval 28 to 42 years. The correlation between diastolic blood pressure and age was highly significant $(P<0.001)$.

\section{Blood pressure and sex}

A comparison between the sexes with regard to the systolic blood pressure, revealed that it was essentially alike in the 8-12- and 13-17-year-old age groups $(P>0.05)$. From the 18-22-year-old age group up to the 38-42-year-old age group, the systolic blood pressure was significantly higher in the male subjects. In the ages above the 48-52-year-old age group the mean value of the systolic blood pressure of the female subjects was significantly higher than the corresponding mean value of the male subjects.
The diastolic blood pressure showed no significant sex differences in the various age groups.

\section{Distribution and dispersion of blood pressures}

The distributions were skewed to the right. This was true for both systolic and diastolic pressures, for both sexes and all age groups. The age- and sexspecific distribution curves remained asymmetrical even after logarithmic transformation.

The dispersion of the systolic and diastolic blood pressures increased with age in both the male and female subjects. From Table 2 it is evident that the dispersions are, above all, increased in the ages above the 38-42-year-old age group.

In the male subjects the coefficients of variation for systolic blood pressure ranged from $7.8 \%$ in the $28-32$-year-old age group to $15.8 \%$ in the $68-72$ year-old age group. The diastolic blood pressure showed the lowest and the highest coefficients of variation, $7 \cdot 1$ and $15.0 \%$ respectively, in the same age groups.

In the female subjects the coefficients of variation for systolic blood pressure ranged from $6.3 \%$ in the $18-22$-year-old age group to $18.3 \%$ in the $53-57$ year-old age group. The diastolic blood pressure showed the lowest and the highest coefficients of variation, $7 \cdot 3$ and $12.2 \%$ respectively, in the same age groups.

\section{Blood pressure and time of measurement}

Older persons attended, to a greater degree, during the morning hours and in winter months, whereas wage earners and school children more often were in attendance early in the morning, after work or school and during the summer. In order to separate

TABLE 2. Systolic and diastolic blood pressures, mean \pm s.d. (mmHg) for male and female subjects within different age groups

\begin{tabular}{|c|c|c|c|c|c|c|c|c|}
\hline \multirow{2}{*}{$\begin{array}{l}\text { Age } \\
\text { group } \\
\text { (years) }\end{array}$} & \multicolumn{4}{|c|}{ Systolic blood pressure } & \multicolumn{4}{|c|}{ Diastolic blood pressure } \\
\hline & (No.) & $\begin{array}{l}\text { Males } \\
(\text { Mean } \pm \text { s.d. })\end{array}$ & (No.) & $\begin{array}{l}\text { Females } \\
(\text { Mean } \pm \text { s.d.) }\end{array}$ & (No.) & $\begin{array}{l}\text { Males } \\
\text { (Mean } \pm \text { s.d.) }\end{array}$ & (Nc.) & $\begin{array}{l}\text { Females } \\
(\text { Mean } \pm \text { s.A. })\end{array}$ \\
\hline $8-12$ & 96 & $113 \cdot 1 \pm 9 \cdot 5$ & 79 & $114 \cdot 2 \pm 7 \cdot 3$ & 96 & $74 \cdot 8 \pm 8 \cdot 0$ & 79 & $75 \cdot 4 \pm 6 \cdot 0$ \\
\hline $13-17$ & 66 & $121 \cdot 1 \pm 12 \cdot 2$ & 67 & $117 \cdot 9 \pm 7.9$ & 66 & $77 \cdot 0 \pm 7 \cdot 3$ & 67 & $78 \cdot 1 \pm 6 \cdot 5$ \\
\hline $18-22$ & 42 & $127 \cdot 3 \pm 14 \cdot 1$ & 53 & $118 \cdot 2 \pm 7 \cdot 4$ & 42 & $80 \cdot 0 \pm 7.0$ & 53 & $77 \cdot 8 \pm 5 \cdot 7$ \\
\hline $23-27$ & 67 & $126 \cdot 9 \pm 10 \cdot 1$ & 75 & $121 \cdot 3 \pm 10 \cdot 9$ & 67 & $81.9 \pm 7.9$ & 75 & $80 \cdot 3 \pm 7 \cdot 4$ \\
\hline $28-32$ & 76 & $124 \cdot 1 \pm 9 \cdot 7$ & 101 & $120 \cdot 5 \pm 9 \cdot 1$ & 76 & $80 \cdot 1 \pm 5 \cdot 7$ & 101 & $78 \cdot 8 \pm 7 \cdot 0$ \\
\hline $33-37$ & 84 & $126 \cdot 4 \pm 12 \cdot 2$ & 69 & $121 \cdot 4 \pm 10 \cdot 6$ & 84 & $82.6+7.8$ & 69 & $80.9+7.7$ \\
\hline $38-42$ & 68 & $126 \cdot 0 \pm 11 \cdot 8$ & 72 & $1217 \pm 12 \cdot 0$ & 68 & $83 \cdot 3 \pm 8 \cdot 3$ & 72 & $81 \cdot 3 \pm 7 \cdot 7$ \\
\hline $43-47$ & 60 & $130 \cdot 6 \pm 13.7$ & 50 & $129 \cdot 0 \pm 15 \cdot 9$ & 60 & $86.0 \pm 9 \cdot 0$ & 50 & $85 \cdot 3 \pm 8 \cdot 4$ \\
\hline $48-52$ & 39 & $134 \cdot 2 \pm 16 \cdot 4$ & 39 & $137 \cdot 1 \pm 20 \cdot 4$ & 39 & $88 \cdot 3 \pm 9 \cdot 6$ & 39 & $88 \cdot 3 \pm 10 \cdot 8$ \\
\hline $53-57$ & 41 & $137 \cdot 4 \pm 16 \cdot 8$ & 32 & $144 \cdot 2 \pm 26 \cdot 4$ & 41 & $89 \cdot 8 \pm 11 \cdot 1$ & 32 & $88 \cdot 3 \pm 10 \cdot 8$ \\
\hline $58-62$ & 50 & $141 \cdot 7 \pm 19 \cdot 3$ & 43 & $152.9 \pm 25.6$ & 50 & $89.5+9.3$ & 43 & $92 \cdot 8+10 \cdot 1$ \\
\hline $63-67$ & 38 & $148 \cdot 0 \pm 20 \cdot 1$ & 39 & $155 \cdot 5 \pm 23 \cdot 7$ & 38 & $92 \cdot 2 \pm 9.9$ & 39 & $92 \cdot 2+10 \cdot 2$ \\
\hline $68-72$ & 27 & $156 \cdot 7 \pm 24 \cdot 7$ & 36 & $158 \cdot 8 \pm 23 \cdot 8$ & 27 & $94 \cdot 1 \pm 14 \cdot 1$ & 36 & $91 \cdot 8+11 \cdot 0$ \\
\hline $73-$ & 26 & $155 \cdot 0 \pm 23 \cdot 2$ & 35 & $170 \cdot 0 \pm 22 \cdot 8$ & 26 & $92 \cdot 9 \pm 11 \cdot 1$ & 35 & $98 \cdot 0 \pm 10 \cdot 2$ \\
\hline
\end{tabular}

Conversion from traditional units to SI units: $1 \mathrm{mmHg} \approx 0.133 \mathrm{kPa}$. 
the effects of the time of measurement from those of age and sex a multiple regression analysis was performed.

At this stage the facts that the relation between systolic blood pressure and age was not linear and that the distribution curves showed a positive skew (see above) had to be taken into account. Therefore, an attempt was made to fit the data also to second and third degree polynomials before and after logarithmic transformation of the blood pressure values (Table 3 ).

Table 3 shows that neither polynomial approximation nor logarithmic transformation resulted in an essential improvement of the correlation between the observed and expected blood pressures. A linear regression analysis was therefore considered adequate-and logarithms unwarranted-for the present purpose.

The goal of the regression analysis was to derive an equation: $y=a+b_{1} x_{1}+b_{2} x_{2}+b_{3} x_{3}+e$ expressing blood pressure ( $y$ or the 'dependent variable') as a mathematical function of age, season and time of day $\left(x_{1}, x_{2}\right.$ and $x_{3}$ or the 'independent variables'), a constant ( $a$, or the ' $y$-intercept') and an error term ( $e$, 'the residual' or the difference between observed blood pressures and blood pressures expected from the independent variables in the equation).

To this end a sequence of regression equations was computed in a stepwise manner. At each step the independent variable which had the highest partial correlation with the dependent variable (i.e. the highest correlation with the residuals) was added to the regression equation. The course of events can be followed in Table 4.

In both sexes the correlations between blood pressure and age were by far the greatest and age was the independent variable entered first in all cases.

The total correlations between season and blood pressure were quite substantial $(0.20$ to 0.26$)$ but, as soon as age had been added to the regression equation, the partial correlations between season and blood pressure were markedly reduced, even though they remained highly significant $(P<0 \cdot 001)$.
The total correlation between time of day and blood pressure was $0 \cdot 11$ for the diastolic pressure in males but very small $(-0.01$ to 0.05$)$ for systolic pressures and in females. When the correlations with age had been taken into account the partial correlations between time of day and systolic blood pressure remained insignificant while the partial correlation between time of day and diastolic blood pressure was increased to 0.13 in females and remained unaltered in males. This meant that the partial correlations between time of day and diastolic blood pressure were highly statistically significant $(P<0.001)$ and in fact greater than those of season in both sexes.

Plots (scattergrams) of the residuals versus the independent variables, provided by the standard computer program, did not disclose any non-linear 'effects' of season or time of day on the blood pressure. Major interactions between time of day and (systolic or diastolic) blood pressures were considered to be ruled out by the fact that the dispersion of the residuals was independent of the time of day.

Thus the multiple regression analysis resulted in the following four equations describing the observed variations of blood pressure with time of measurement in the present material.

Systolic blood pressure in males $=108.0+0.53 \times$ age $+4 \cdot 1 \times$ season.

Systolic blood pressure in females $=98 \cdot 8+0.76 \times$ age $+5.0 \times$ season.

Diastolic blood pressure in males $=68 \cdot 7+0 \cdot 28 \times$ age $+1 \cdot 7 \times$ season $+0 \cdot 24 \times$ time of day.

Diastolic blood pressure in females $=67.0+0.31 \times$ age $+1.9 \times$ season $+0.27 \times$ time of day.

In other words: when the effect of age on blood pressure was eliminated the systolic blood pressure was found to be $4.1(5.0)$-and the diastolic 1.7 (1.9), mmHg higher in men (women) during the winter-half of the year. The time of day had no influence on the systolic pressure but the diastolic pressure increased during the waking hours by 0.24 and $0.27 \mathrm{mmHg} / \mathrm{hr}$ in male and female subjects respectively.

TABLE 3. Correlation between observed values and blood pressures expected from age after polynomial approximation

\begin{tabular}{|c|c|c|c|c|c|}
\hline & \multirow{2}{*}{$\begin{array}{l}\text { Degree of } \\
\text { polynomial }\end{array}$} & \multicolumn{2}{|c|}{ Systolic blood pressure } & \multicolumn{2}{|c|}{ Diastolic blood pressure } \\
\hline & & not transf. & $\log$ transf. & not transf. & $\log$ transf. \\
\hline Males & $\begin{array}{l}1 \\
2 \\
3\end{array}$ & $\begin{array}{l}0.582 \\
0.589 \\
0.592\end{array}$ & $\begin{array}{l}0.591 \\
0.594 \\
0.598\end{array}$ & $\begin{array}{l}0.539 \\
0.540 \\
0.540\end{array}$ & $\begin{array}{l}0.543 \\
0.545 \\
0.545\end{array}$ \\
\hline Females & $\begin{array}{l}1 \\
2 \\
3\end{array}$ & $\begin{array}{l}0.686 \\
0 \cdot 719 \\
0 \cdot 720\end{array}$ & $\begin{array}{l}0.699 \\
0.726 \\
0.727\end{array}$ & $\begin{array}{l}0.589 \\
0.593 \\
0.597\end{array}$ & $\begin{array}{l}0.584 \\
0.587 \\
0.590\end{array}$ \\
\hline
\end{tabular}


TABLE 4. Multiple regressions of arterial blood pressure on age, season and time of day

A. Coefficients of total and partial correlations between sYSTOLIC blood pressure and independent variables in MALES

\begin{tabular}{lccc}
\hline & \multicolumn{2}{c}{$\begin{array}{c}\text { Independent variables added to the } \\
\text { regression equation }\end{array}$} \\
\cline { 2 - 4 } $\begin{array}{l}\text { Independent } \\
\text { variable }\end{array}$ & None & Age & $\begin{array}{c}\text { Age and } \\
\text { season }\end{array}$ \\
\hline Age & 0.58 & - & - \\
Season & 0.23 & 0.14 & - \\
Time of day & 0.05 & 0.04 & 0.03 \\
\hline
\end{tabular}

B. Coefficients of total and partial correlations between SYSTOLIC blood pressure and independent variables in FEMALES

Independent variables added to the regression equation

\begin{tabular}{lccc}
\cline { 2 - 4 } $\begin{array}{l}\text { Independent } \\
\text { variable }\end{array}$ & None & Age & $\begin{array}{c}\text { Age and } \\
\text { season }\end{array}$ \\
\hline Age & 0.69 & - & - \\
Season & 0.26 & 0.15 & - \\
Time of day & -0.01 & 0.08 & 0.06 \\
\hline
\end{tabular}

C. Coefficients of total and partial correlations between DIASTOLIC blood pressure and independent variables in MALES

\begin{tabular}{lccc}
\hline & \multicolumn{2}{c}{$\begin{array}{c}\text { Independent variables added to the } \\
\text { regression equation }\end{array}$} \\
\cline { 2 - 4 } $\begin{array}{l}\text { Independent } \\
\text { variable }\end{array}$ & None & Age & $\begin{array}{c}\text { Age and } \\
\text { time of day }\end{array}$ \\
\hline Age & 0.54 & - & - \\
Time of day & 0.11 & 0.11 & - \\
Season & 0.20 & 0.11 & 010 \\
\hline
\end{tabular}

D. Coefficients of total and partial correlations between DIASTOLIC blood pressure and independent variables in FEMALES

Independent variables added to the regression equation

\begin{tabular}{lccc}
$\begin{array}{lccc}\text { Independent } \\
\text { variable }\end{array}$ & None & Age & $\begin{array}{c}\text { Age and } \\
\text { time of day }\end{array}$ \\
\hline Age & 0.59 & - & - \\
Time of day & 0.05 & 0.13 & - \\
Season & 0.23 & 0.12 & 0.11 \\
\hline
\end{tabular}

\section{Discussion}

The Dalby population was invited to attend an ophthalmological examination. It was not mentioned that it was intended to measure the blood pressure. It was felt that this omission would lessen the risk of the subjects refusing participation because they were afraid to have their blood pressures measured.
Among those attending, $7 \%$ were subsequently excluded, half of these because they were taking diuretics or other antihypertensive drugs, the other half for other reasons unrelated to the blood pressure. Therefore the results are based on $82 \%$ of the invited population. In the different groups under 70 years of age, the participation varied between 75 and $92 \%$. It was appreciably lower in the oldest age groups. In other population studies of the blood pressure, it cannot be excluded that a certain portion of the loss in participants might be caused by the fact that the invitation had specified that the blood pressure was going to be measured (Berglund, 1974).

The blood pressure values in the present study agreed with corresponding values in other population studies (Hamilton et al., 1954; Comstock, 1957; Eilertsen and Humerfelt, 1968). The increase in systolic blood pressure with age was not linear. The blood pressures rose to a plateau with essentially unchanged pressures in the interval 28 to 42 years. In these ages, the systolic blood pressure was significantly higher in the male subjects. In older subjects, the increase in systolic blood pressure was most pronounced in the females. There were no sex differences in the diastolic blood pressure.

The systolic and diastolic blood pressures in the various age groups were not normally distributed Even after logarithmic transformation, the distris bution curves were skewed. Despite the fact that the total material included 1570 individuals, the number of individuals in the different age groups was too small to ascertain if the positive skewing of the curves was conditioned by the occurrence of more than one population or by other factors.

Previous reports have emphasized the importance of variations in blood pressure with the time of measurement (National Health Survey, 1964; Berglund, 1974; Hardy, Cutter and Hawkins, 1976). Such variations were encountered also in the present study. However, the variations could be shown to be largely dependent on the fact that the invited subjects were allowed to choose freely the time for the examination. The preferred time for examination was strongly dependent on age and sex and since the blood pressure varied with age the variations with the time of measurement were partly caused (or counteracted) by variations with age and sex. Such effects do not seem to have been analysed previously. They may explain some apparent discrepancies between earlier reports.

When the effect of age on the blood pressure had been eliminated the genuine effects of the time of measurement were found to be rather small. The authors feel that these lack practical importance even if they are highly significant from a statistical point of view. 
In screening hypertension, it can thus be accepted that the individuals in a population are going to come at different times of the day for the examination. It is not necessary to counteract this selection effect.

\section{Acknowledgments}

The statistical co-operation of $\mathrm{Mr}$ Arne Sundström made this study possible with the aid of the data service at the Computer Centre in Lund.

\section{References}

Athanassiadis, D., Draper, G.J., Honour, A.J. \& CranSTON, W.I. (1969) Variability of automatic blood pressure measurements over 24 hour periods. Clinical Science, 36, 147.

BengtsSon, B. (1972) Some factors affecting the distribution of intraocular pressures in a population. Acta ophthalmologica, 50, 33.

Berglund, G. (1974) Hypertoni och Hypertensiva Organmanifestationer hos 50-åriga Män. Erlanders Boktryckeri AB, Kungsbacka.

Bü̈rck, Å. \& Dahlkvist, G. (1974) Numerical Analysis. First edn. Englewood Cliffs, New Jersey.

Bøe, J., Humerfelt, S. \& Wedervang, F. (1957) The blood pressure in a population. Acta medica scandinavica, Suppl. 321.

Brown, G.E. (1930) Daily and monthly rhythm in the blood pressure of a man with hypertension: A three-year study. Annals of Internal Medicine, 3, 1177.

Comstock, G.W. (1957) An epidemiologic study of blood pressure levels in a biracial community in the southern United States. American Journal of Hygiene, 65, 271.

Dixon, W.J. (1970) B.M.D. Biomedical Computer Programs. Second edn. University of California Press, Berkeley, Los Angeles and London.

Eilertsen, E. \& Humerfelt, S. (1968) The blood pressure in a representative population sample. Acta medica scandinavica, 183, 293.

EPSTEIN, F.H. (1960) An epidemiological study in a total community: The Tecumseh project. University of Michigan Medical Bullerin, 62, 307.

Farmaceutiska Specialiteter i Sverige ('FASS') (1969) Almqvist and Wiksell, Uppsala.
Hamilton, M., Pickering, G.W., Fraser Roberts, J.A. \& SOWRY, G.S.C. (1954) The aetiology of essential hypertension. 1. The arterial pressure in the general population. Clinical Science, 13, 11.

Hardy, R.J., Cutter, G.R. \& Hawkins, C.M. (1976) Sodium excretion and sympathetic activity in relation to severity of hypertensive disease. The Lancet, ii, 471.

Irving, J.B., Kerr, F., Ewing, D.J. \& Kirby, B.J. (1974) Value of prolonged recording of blood pressure in assessment of hypertension. British Heart Journal, 36, 859.

Kagan, A., Gordon, T., Kannel, W.B. \& Dawber, T.R. (1958) Blood pressure and its relation to coronary heart disease in the Framingham study. In: Hypertension, VII, Proceedings of the Council for High Blood Pressure Research, American Heart Association.

Kain, H.K., Hinman, A.T. \& Sokolow, M. (1964) Arterial blood pressure measurements with a portable recorder in hypertensive patients. Circulation, 30, 882.

LUNDS KOMMUN: STATISTISK ÅRSBOK (1972) Litos Reprotryck, Malmö.

Miall, W.E. \& Lovell, H.G. (1967) Relation between change of blood pressure and age. British Medical Journal, 2,660 .

National Health Survey: Public Health Service Publications (1964) No. 1000, Ser. 11, No. 4, Washington, D.C.

Palmai, G. (1962) Skin-fold thickness in relation to body weight and arterial blood pressure. The Medical Journal of Australia, 49, 13.

Paul, O., Lepper, M.H., Phelan, W.H., Dupertuis, G.W., MacMillan, A., McKean, H. \& Park, H. (1963) A longitudinal study of coronary heart disease. Circulation, 28, 20.

Richardson, D.W., Honour, A.J., Fenton, G.W., Stott, F.H. \& Pickering, G.W. (1964) Variation in arterial pressure throughout the day and night. Clinical Science, 26, 445.

Rose, G. (1961) Seasonal variation in blood pressure in man. Nature. London, 189, 235.

Sasaki. N., Takeda, J., Fukushi, S., Hasunuma, M., IChIKaWa, H., Ichinohe, M., TanaKa, K., SaSaki, I., Takei, T., Sugita, K., Takemori, K. \& Yamada, N. (1969) Seasonal variation in the blood pressure of the inhabitants in the northeastern parts of Japan. The Hirosaki Medical Journal, 21, 202.

Statistisk ÅRsBok 1970 (1970) Norstedt \& Söner, Stockholm. 